\title{
Minor Axis Cross-sectional Diameter at Mid Ventricular Systole
}

National Cancer Institute

\section{Source}

National Cancer Institute. Minor Axis Cross-sectional Diameter at Mid Ventricular Systole. NCI Thesaurus. Code C139052.

The cross-sectional diameter of a cardiovascular structure measured along its minor axis at mid ventricular systole. 